\title{
LA INVESTIGACIÓN CIENTÍFICA Y SU APROPIACIÓN POR LA SOCIEDAD
}

\author{
Tito Ureta*
}

* Profesor titular del Departamento de Biología. Facultad de Ciencias, Universidad de Chile 


\section{RESUMEN}

El artículo revela la dificultad de la sociedad chilena para apropiarse del conocimiento científico, pese al uso intensivo que hace de la tecnología. Además de destacar la importancia de esta apropiación para la sociedad en su conjunto, el autor apunta hacia algunas causas de esta dificultad, tales como: la mala calidad de la educación chilena, la especialización precoz -tanto de estudiantes como de profesionales-y lo inaccesible del lenguaje de los especialistas, fenómeno que obliga a contar la mayoría de las veces con malos intermediarios. Concluye con algunas ideas sobre qué pueden hacer los científicos para lograr una efectiva divulgación de sus resultados.

\section{ABSTRACT}

The paper reveals the difficulties that Chilean society faces in appropriating scientific knowledge despite its intensive use of technology. In addition to emphasizing the importance of such appropriation for society as a whole, the author points to some of the underlying reasons of this difficulty, such as the poor quality of Chilean education, an extremely premature specialization -both in the case of students as well as in that of professionals- and the inaccessibility of the language of specialists, a fact that frequently requires resorting to poor intermediaries. The paper ends with some ideas about what scientists can do to achieve effective dissemination of their research results. 


\section{LA INVESTIGACIÓN CIENTÍFICA Y SU APROPIACIÓN POR LA SOCIEDAD}

Los sorprendentes logros de la ciencia en la segunda mitad del siglo pasado han resultado en un aumento sin precedentes en la calidad de vida de los países desarrollados y en aquellos que pretenden serlo en el futuro cercano. Además de los avances en las ciencias básicas, que sirven de fundamento para una imago mundi sólida e integrada, hemos asistido a un explosivo desarrollo de nuevos inventos en comunicaciones, transporte, alimentación, entre otros ámbitos (la lista es muy larga), que no parece detenerse. Paralelamente, esos avances se acompañan con la aparición de problemas prácticos (polución ambiental, por sólo nombrar uno) y valóricos, como la desaparición acelerada de etnias, la fertilización asistida, los alimentos transgénicos y la clonación, por sólo nombrar algunos (también una lista interminable). No es extraño, por lo tanto, que, junto con las bendiciones y maldiciones intrínsecas al avance científico tecnológico, aparezca la necesidad del público general por entender qué está pasando en ciencia, por conocer mejor los nuevos electrodomésticos que se le ofrecen o, quizás en menor grado, por participar activamente en la aventura del conocer. Nunca antes la ciencia había tenido un perfil público tan alto.

Es claro que la apropiación de la ciencia por la sociedad es una actitud que debiera aplaudirse y fomentarse. En primer lugar, porque es una actitud profundamente democrática, ya que "todos" debiéramos tener acceso a los descubrimientos que nos permiten una mejor visión del mundo que nos rodea. Luego, porque entender nos permite mejores decisiones acerca de nuestro estilo de vida. Por último, porque la apropiación de la ciencia debiera ser una influencia poderosa para las decisiones políticas acerca del financiamiento de las actividades 
científicas y del urgente mejoramiento de la educación, condición sine qua non para la apropiación.

No obstante lo dicho, la sociedad chilena no se ha percatado de la necesidad de esta apropiación y, por lo tanto, no ha logrado mejorar su imagen del mundo o entender las bases que le permitirían decisiones racionales acerca de los problemas valóricos que la ciencia le propone (basta observar el nivel de la discusión en diarios, revistas y televisión, sobre la llamada "píldora del día después"). La población general sigue pulsando mecánicamente los botones de su teléfono móvil o del reproductor de películas o de discos compactos, o del control remoto del televisor o las teclas del computador, sin siquiera preguntarse por qué pasan las cosas que pasan al presionar los botones. Aún más preocupante es que ni siquiera se le pasa por la mente preguntárselo. Las cosas pasan simplemente porque pasan y eso es lo único que importa. Los ciudadanos de nuestro país suelen ser, en su gran mayoría, analfabetos científicos.

Las razones que explican la indiferencia con que el hombre y mujer corrientes de nuestro país se enfrentan a los avances de la ciencia son múltiples y de diversa índole. No es posible, en un breve trabajo como éste, pasar revista a todos, por lo que sólo me referiré a los que considero más importantes.

La mala calidad de la educación chilena

Todos los indicadores nos gritan que nuestra educación básica y media pasa por un mal momento. No hago diferencia entre educación pública y privada. Mi experiencia con jóvenes que llegan a la universidad me sugiere que sólo unos pocos de esos muchachos tienen la disposición y los conocimientos que les permitirían desempeñarse sin problemas en los primeros años de la educación superior. No es éste el lugar para el análisis global de la educación chilena ni para proponer las medidas que debieran adoptarse para despertar, en niños y adolescentes, la curiosidad indispensable para insertarse provechosamente en la sociedad y construir su propio futuro. Tampoco me refiero aquí a la apropiación de la ciencia, sino simplemente a la apropiación de la curiosidad por todo. Los profesores de cualquiera asignatura debieran mantenerla, ya que 
todos los niños normales la tienen, pero la pierden paulatinamente, quizás por métodos didácticos equivocados o porque ellos mismos ya la perdieron y, por lo tanto, no pueden transmitirla.

La experiencia acumulada en varios países (para una breve relación, véase Lipkin, 2000) muestra que es posible combinar conocimiento e información para producir un sistema que permita enseñar la lectura al 95\% de un curso heterogéneo (de 40 niños de seis años de edad), a entender textos escritos y convertirse en educandos independientes, utilizando un solo profesor y sin ayuda de los padres. ¿Por qué no podemos hacerlo también en nuestro país?

\section{La especialización precoz y sus consecuencias}

Los jóvenes de la educación media comienzan temprana y espontáneamente a especializarse. Los padres suelen constatar que sus hijos manifiestan preferencias por algunas ramas del saber humano; pero, en vez de intervenir activamente por lograr una educación amplia, se escudan en la creencia determinística de suponer que su hijo "no es bueno para las matemáticas" (o para cualquiera otra disciplina). Con ello, los muchachos, tempranamente, dirigen su esfuerzo sólo a algunas materias y dejan de aprender otras que serían esenciales para lograr una imagen integrada del mundo. Luego, ingresan a los tubos inconexos que suelen ser las carreras universitarias y egresan sabiendo mucho acerca de muy poco y, lo que es peor, sin que les importe o preocupe. Los que optaron por carreras de corte humanístico se encogen de hombros cuando alguien les propone algún tema de ciencia. Los que eligieron una carrera científica no se percatan siquiera de la belleza de la filosofía y de las artes. De ello resulta la incapacidad de apropiarse del conocimiento, sea científico o humanístico y, por lo tanto, persisten en apretar los botones que les permiten sobrevivir.

Las actitudes descritas resultan en lo que C.P. Snow llamó Las Dos Culturas, según el título de su famosa conferencia Rede (y su pequeño libro basado en la charla). Su tesis central es que entre científicos y humanistas se ha creado un abismo de incomunicación, fatal para aquellos que quisieran tejer una visión integrada y global que les permita una vida armoniosa. No existen puentes para salvar la brecha, excepto una educación que no desdeñe ni una ni otra esfera 
del esfuerzo humano. Me he referido a este problema con anterioridad (Ureta, 2000) con el agregado de que, a mi juicio, la incomunicación va mucho más allá de lo que Snow imaginó. Ahora se extiende a lo que llamé ene culturas. Es sabido que sociólogos, filósofos y artistas ya no se comunican entre ellos. Los físicos, químicos y biólogos apenas se entienden entre sí y los matemáticos sólo se entienden a sí mismos.

Visualizo dos maneras de tender puentes entre las ene culturas. Una es, por cierto, la educación precoz, pero en vista de la situación actual no creo que lo logre. También podríamos, en el ámbito universitario, tomar algunas medidas para atravesar el abismo. Desde luego flexibilizar las mallas curriculares para permitir a los alumnos tomar cursos de otras facultades o escuelas. Los programas de Bachillerato, esto es: ingreso indiferenciado a la universidad postergando la elección de la carrera definitiva en un par de años, debieran ser importantes para el fin deseado. Desgraciadamente, esos programas sólo existen en unas pocas universidades y no ha habido voluntad política para implementarlos como única manera de ingreso a la educación superior. Para colmo de males, existen programas de Bachillerato que se ofrecen en dos vertientes: científicas o humanísticas (!), lo que, en el contexto que estamos examinando, es un contrasentido absoluto.

Algunas universidades, recientemente, han reformulado sus planes de estudio insertando cursos de formación general que dan a los estudiantes la posibilidad de conocer los grandes temas de la cultura (tanto en ciencias como en humanidades y artes). Tendrán éxito si el número obligatorio de esos cursos es el apropiado y si evitan que los alumnos sólo elijan aquellos con los temas más cercanos a sus carreras profesionales.

La inaccesibilidad de la ciencia (o de las humanidades)

La especialización a la que nos hemos referido lleva consigo la aparición de dialectos inteligibles sólo para iniciados (Camba, 2000). Si alguien medianamente educado toma una revista científica general para enterarse de lo que allí se publica tendrá que abandonar su noble intento casi sin haber empezado. La empresa no tiene sentido si se elige una revista científica especializada. En efecto, los científicos deben 
describir sus hipótesis, experimentos, resultados y conclusiones en el menor número posible de palabras y en el estilo más impersonal posible. Por ello, no es de extrañar la aparición de jergas comprensibles sólo para los especialistas de la disciplina. Pero ello no sólo ocurre en las ciencias llamadas duras. Un artículo o libro sobre filosofía es una empresa que muy rara vez está al alcance de los no-filósofos. A pesar de varios intentos, solamente he logrado entender (a medias) a Ludwig Wittgenstein, que no era precisamente un filósofo tradicional. Por esta razón, no es posible para el público general informado recibir de primera mano lo que los científicos están descubriendo. Existen algunas revistas que publican artículos escritos por científicos pero destinados al público general. Suelen iniciar sus actividades apropiadamente, es decir, editando los escritos de manera que efectivamente estén escritos sin jerga y sin los detalles que sólo interesan a los especialistas en el tema. Rápidamente olvidan su vocación y, al cabo de pocos años, se hacen paulatinamente inaccesibles (véase un interesante estudio cuantitativo de Hayes, 1992). Otras revistas intentan captar al público mediante artículos escritos especialmente con ese objeto, generalmente por personas que no se dedican directamente a la ciencia, pero que tienen la capacidad de entender lo que los científicos escriben o dicen. Sólo muy pocas logran el objetivo (destaco especialmente La Recherche y algunas secciones de Science). Otras son directamente un desastre. Para atraer al público incluyen artículos vendedores con temas como ovnis, curaciones milagrosas o fenómenos telepáticos.

¿Por qué no pueden los científicos escribir a un nivel comprensible por todos? La verdad es que plantearse preguntas, imaginar hipótesis, diseñar y realizar experimentos es una labor que exige años de preparación y que se logra sólo mediante una dedicación exclusiva a esas tareas. Nunca hay tiempo suficiente, especialmente si se agrega que un científico exitoso debe conseguir por sí mismo el financiamiento de los proyectos que quiere realizar. Finalmente, la visibilidad de un científico entre sus pares se mide casi exclusivamente por los artículos especializados que publica. La extensión de su conocimiento al público general no cuenta para su promoción o salario. Son muy pocos los científicos activos que han tenido éxito por su actividad científica y la divulgación de la ciencia a la vez (los más conocidos son Stephen Jay Gould y Richard Dawkins). 
Otra dificultad importante en esto de comunicar ciencia tiene que ver con el uso del inglés como lingua franca de los científicos. Puede no gustarnos pero, en el momento actual, el inglés es casi la única forma de entenderse en ciencias. Una consecuencia de esto es que, más a menudo de lo que uno quisiera, el español que usan los científicos se llena de anglicismos que, en casos extremos, se convierte en un atroz galimatías.

Un problema central es que la entrega de conocimiento por parte de los científicos generalmente se reduce a comunicar hechos experimentales para luego murmurar que esos resultados podrían tener importancia para resolver problemas de la sociedad, para curar enfermedades, proteger a los animales o al medio ambiente. Se olvida que la gran mayoría de los avances importantes no han resultado del deseo de mejorar a la sociedad, sino que provienen simplemente de la curiosidad humana. Quizás el éxito del libro de James Watson, acerca del descubrimiento de la doble hélice del ácido desoxirribonucleico, se debe a que relata su genial experiencia tal como ocurrió, y es capaz de transmitir al público la enorme excitación del descubrir (véase Judson [1996] para captar esos momentos de pulso acelerado a tambor batiente).

Por el lado de las humanidades la situación no es diferente. No es posible pedirle a un filósofo que describa su filosofar utilizando sólo las tres mil palabras que, se dice, son las que una persona corriente requiere para entender un periódico.

Quizás no sería imposible revertir, aunque sea parcialmente, la situación descrita. Las universidades podrían crear cursos electivos que permitan a los científicos en ciernes aprender técnicas de comunicación que les ayudaran a entregar sus conclusiones en la forma apropiada y para satisfacción de todos.

Concluyo esta sección con la afirmación de que los especialistas no son capaces de entregar directamente su saber para que la sociedad pueda apropiarse de ese conocimiento.

La necesidad de intermediarios en la divulgación de la ciencia

Algunas disciplinas disponen de un intermediario que informa al público acerca de las creaciones. Es, por ejemplo, el caso del crítico de 
arte. Eso tiene sentido, porque los compositores y los pintores trabajan en dominios del pensamiento para los cuales el dominio lingüístico no es el apropiado (recuérdese la anécdota en que se cuenta que después de escuchar la Sonata Claro de Luna alguien le pide a Beethoven que la explique. La respuesta del músico fue volver al piano y ejecutar la sonata una segunda vez). No existe en el ámbito científico o humanístico una contraparte del crítico de arte. Lo que sí existe es el periodista científico. Efectivamente, en vista del interés del público, diarios y revistas suelen incluir noticias científicas en sus ediciones. Pero muy pocas universidades chilenas ofrecen, en las mallas curriculares de las escuelas de periodismo, cursos sobre periodismo científico o actividades de posgrado relacionadas. En nuestro país se pueden contar con los dedos de una mano los periodistas especializados en asuntos científicos. La mayoría normalmente transcribe lo que las agencias le proporcionan. En algunos casos recurren a algún científico amigo o de buena voluntad para que les explique los detalles o las conclusiones de alguna noticia que perciben como interesante. Entonces solicitan que la explicación sea lo más breve posible ("por favor, doctor, no más de cinco líneas") y, además, con un plazo de un par de horas ("usted sabe que tenemos hora de cierre"). Luego, algún otro profesional abrevia lo escrito y, por lo tanto, la explicación deja de ser tal. La situación lleva a que los científicos rehúyan a la prensa y, por ello, el público recibe las noticias científicas sin que le sea posible entenderlas.

La conclusión es que, desgraciadamente, no existe en Chile un intermediario capaz de informar al público general acerca de los avances científicos y su relación con la sociedad. Los periodistas no sólo informan mal sobre lo que ocurre en ciencia en el ámbito mundial, sino que tampoco siguen los avances producidos en nuestro país, quizás porque creen, equivocadamente, que en Chile no se producen descubrimientos que valgan la pena.

¿Qué pueden hacer los científicos para lograr que la sociedad se apropie de la ciencia?

Para producir un cambio en la situación descrita existe una medida de largo plazo: mejorar de verdad la educación básica y media. La tarea debe quedar en las manos de los expertos y, en todo caso, los 
resultados tardarán muchos años en notarse. Las medidas a mediano plazo son poco posibles. Los currículos de las carreras profesionales, y también de las licenciaturas en ciencia, están tan atiborrados, que introducir cursos para preparar a los jóvenes en comunicar bien lo que saben implica eliminar materias de las especialidades. Sabemos que, en este respecto, las universidades chilenas (también las del extranjero) son extremadamente conservadoras y, por lo tanto, mal dispuestas a eliminar contenidos o comprimir su enseñanza. Quizás son las medidas a corto plazo las que permitirían la entrega real de contenidos científicos al público general. En efecto, sería relativamente fácil detectar, entre los científicos activos, aquéllos con interés por la divulgación de la ciencia y entrenarlos para ese efecto, y con los estímulos adecuados. Los departamentos de extensión de las universidades podrían ofrecer cursos para público general utilizando precisamente a esos investigadores. Las grandes universidades, también llamadas complejas, que cuentan con el mayor número de científicos, podrían organizar cursos itinerantes para zonas menos desarrolladas del país. Lo importante es que el nivel de tales cursos sea apropiado y que los contenidos enganchen con los intereses de los participantes. Los cursos de divulgación en cosmología son ideales para esos propósitos, pero hay otros posibles de imaginar como, por ejemplo, los problemas valóricos de la clonación (que ya viene), el origen del humano y de los seres vivos. 


\section{REFERENCIAS BiBLIOGRÁFICAS}

Camba, R., "Start making sense. Scientists must stop isolating themselves behind walls of jargon", en Nature 406, 2000, p. 461.

Hayes, D.P., "The growing inaccessibility of science", en Nature 356, 1992, pp. 739-40.

Judson, H.F., The Eighth Day of Creation. Makers of the Revolution in Biology, Expanded Edition, Cold Spring Harbor Laboratory Press, New York, 1996.

Lipkin, H.J., The structure of matter. Like science, teaching should be the result of independent ideas converging, en Nature 406, 2000, p. 127.

Snow, C.P., Las Dos Culturas y un Segundo Enfoque, Alianza Editorial, Madrid, 1977.

Ureta, T., "Una cultura, dos culturas, ene culturas", en U Noticias, julio-agosto 2002. 
